\title{
A randomized trial to assess the impact of an antithrombotic decision aid in patients with nonvalvular atrial fibrillation: the DAAFI trial protocol [ISRCTNI 4429643]
}

Finlay A McAlister*1, Malcolm Man-Son-Hing2, Sharon E Straus ${ }^{3}$, William A Ghali ${ }^{4}$, Paul Gibson ${ }^{4}$, David Anderson ${ }^{5}$, Jafna Cox ${ }^{5}$, Miriam Fradette 6 and the Decision Aids in Atrial Fibrillation (DAAFI) Investigators

Address: ${ }^{1}$ The Division of General Internal Medicine, University of Alberta, Edmonton, Canada, ${ }^{2}$ Elisabeth Bruyere Research Institute and Geriatric Medicine, University of Ottawa, Ottawa, Canada, ${ }^{3}$ The Divisions of Geriatric and General Internal Medicine, University of Toronto, Toronto, Canada, ${ }^{4}$ General Internal Medicine, University of Calgary, Calgary, Canada, ${ }^{5}$ Department of Medicine, Dalhousie University and Capital Health, Halifax, Canada and ${ }^{6}$ The Epidemiology Coordinating and Research Centre, University of Alberta, Edmonton, Canada

Email: Finlay A McAlister* - Finlay.McAlister@ualberta.ca; Malcolm Man-Son-Hing - mhing@ohri.ca; Sharon E Straus - sstraus@mtsinai.on.ca; William A Ghali - wghali@ucalgary.ca; Paul Gibson - gibsonp@ucalgary.ca; David Anderson - david.anderson@dal.ca; Jafna Cox - icjc@ICONS.QE2-HSC.NS.CA; Miriam Fradette - miriam.fradette@ualberta.ca; the Decision Aids in Atrial Fibrillation (DAAFI) Investigators -

* Corresponding author

Published: 05 May 2004

BMC Cardiovascular Disorders 2004, 4:5

This article is available from: http://www.biomedcentral.com/|47|-226I/4/5

(C) 2004 McAlister et al; licensee BioMed Central Ltd. This is an Open Access article: verbatim copying and redistribution of this article are permitted in all media for any purpose, provided this notice is preserved along with the article's original URL.
Received: 3I March 2004

Accepted: 05 May 2004

\begin{abstract}
Background: Decision aids are often advocated as a means to assist patient and health care provider decision making when faced with complicated treatment or screening decisions. Despite an exponential growth in the availability of decision aids in recent years, their impact on long-term treatment decisions and patient adherence is uncertain due to a paucity of rigorous studies. The choice of antithrombotic therapy for nonvalvular atrial fibrillation (NVAF) is one condition for which a trade-off exists between the potential risks and benefits of competing therapies, and the need to involve patients in decision making has been clearly identified. This study will evaluate whether an evidence-based patient decision aid for patients with NVAF can improve the appropriateness of antithrombotic therapy use by patients and their family physicians.

Design: A multi-center, two-armed cluster randomized trial based in community family practices in which patients with NVAF will be randomized to decision aid or usual care. Patients will receive one of four decision aids depending on their baseline stroke risk. The primary outcome is the provision of "appropriate antithrombotic therapy" at 3 months to study participants (appropriateness defined as per the 200I American College of Chest Physicians recommendations for NVAF). In addition, the impact of this decision aid on patient knowledge, decisional conflict, well-being, and adherence will be assessed after 3 months, 6 months, and 12 months.
\end{abstract}




\section{Background \\ Atrial fibrillation and anti-thrombotic therapy - the evidence}

Atrial fibrillation (AF) is a common cardiac arrhythmia, with a prevalence approaching $2 \%$ in the general adult population [1]. The incidence of atrial fibrillation increases sharply with age: three-quarters of all patients with atrial fibrillation are over the age of 65 [1-3]. Patients with atrial fibrillation have a mortality rate nearly double that of age and sex matched controls without atrial fibrillation, largely due to an increased risk of stroke and systemic emboli [1]. In fact, the risk of stroke in the average patient with nonvalvular atrial fibrillation (NVAF) is approximately 5\% per year (a five-fold increase in risk compared to age and sex-matched controls with sinus rhythm) [4], and $43 \%$ to $73 \%$ of cardioembolic strokes result in death or severe neurologic deficit [5].

In the past decade a number of randomized trials have clearly established that warfarin (relative risk reduction [RRR] $62 \%$, 95\% confidence intervals $48 \%$ to $72 \%$ ), and to a lesser extent acetylsalicylic acid (ASA) (RRR 22\%, $95 \%$ confidence intervals $2 \%$ to $38 \%$ ), are highly efficacious in the prevention of cardioembolic events in patients with NVAF [6]. An individual patient meta-analysis incorporating six of the NVAF trials highlighted the importance of determining baseline stroke risk in patients with NVAF given the trade-off between the greater efficacy of warfarin (hazard ratio for stroke versus ASA of 0.55 , 95\% CI 0.43-0.71) and the increased bleeding risk (nearly two fold greater than with ASA) [7]. Thus, in patients at high risk for stroke, warfarin was clearly more beneficial than ASA, while in patients at low risk for stroke, the bleeding risk of warfarin outweighed the potential benefits. This trial evidence is supported by health outcomes studies which confirmed the RRR for warfarin and ASA when used in real world settings is similar to that observed in trials [8-13], and a cost-effectiveness analysis showing that the provision of warfarin therapy to NVAF patients with additional stroke risk factors is highly cost-effective [14].

However, antithrombotic therapy is not without risks or inconveniences. For example, antithrombotic therapy may impose a number of lifestyle constraints upon patients (such as the need for regular International Normalized Ratio [INR] monitoring and the avoidance of potentially hazardous recreational activities when taking warfarin). Perhaps more importantly, antithrombotic therapy carries a risk of bleeding (particularly with warfarin). While the risk of major hemorrhage was only minimally increased in warfarin-treated patients in the NVAF trials $(1.3 \%$ per year versus $1 \%$ per year in placebo-treated patients), 53-93\% of screened patients were excluded from these trials because of perceived increased bleeding risk [6].

\section{Risk stratification in the patient with NVAF}

As patients differ in their stroke risks at baseline (and thus differ in their potential to benefit from antithrombotic therapy), it would be inappropriate to make a blanket recommendation that all NVAF patients take one therapy or the other. However, analyses of the pooled data from the NVAF trials identified a risk stratification scheme which allows antithrombotic recommendations to be tailored to the specifics of each case $[15,16]$. Table 1 outlines a modification of this risk stratification scheme and the 2001 American College of Chest Physicians (ACCP) antithrombotic recommendations for NVAF patients [5]. For the purposes of this study, treatment will be defined as "appropriate" if it conforms to the 2001 ACCP recommendations for a patient in that risk strata (for patients on warfarin, the INR must be in the therapeutic range of 23).

\section{Evidence of a care gap}

Practice audits and physician surveys in various settings have consistently shown that less than half of eligible patients with NVAF receive antithrombotic therapy. Moreover, even in those who are prescribed warfarin, INRs are only therapeutic approximately half of the time [10$13,17]$.

While the decision to initiate lifelong anticoagulant therapy does (and should) depend on individual patient preferences and some patients may decline proven efficacious therapies, the weight of evidence in NVAF suggests that most patients with this condition express clear desires to avoid stroke and are more willing to take warfarin therapy than their physicians are to prescribe it [18-23]. While $96 \%$ of Canadian physicians agreed that patients should receive information on the benefits and risks of warfarin and $86 \%$ felt that patients should have a say in whether warfarin is prescribed, the most frequently cited barriers to the prescription of warfarin in patients with NVAF were "patient related barriers" [24]. In particular, the most frequently cited barrier was that "patients would prefer not to take warfarin due to interference with lifestyle" (72\% of physician respondents) [24]. Other surveys have demonstrated that clinicians tend to underestimate the benefits and overestimate the risks of anticoagulation therapy in atrial fibrillation [25-27].

\section{The potential role of patient-mediated interventions in closing care gaps}

Numerous studies have suggested that improving patient knowledge and encouraging their active participation in treatment decisions may improve their quality of life, their satisfaction with care, and their compliance with 
Table I: Baseline stroke risk stratification and recommended antithrombotic therapy for patients with nonvalvular atrial fibrillation

\begin{tabular}{|c|c|c|c|}
\hline Strata & Clinical factors & $\begin{array}{l}\text { Estimated bi-annual stroke } \\
\text { risk (\%) }\end{array}$ & $\begin{array}{l}2001 \text { ACCP recommended } \\
\text { therapy }[5]\end{array}$ \\
\hline Low & $\begin{array}{l}\text { Age }<65 \text { years, no history of hypertension, heart } \\
\text { failure or reduced LVEF, or prior systemic emboli }\end{array}$ & 2 & ASA \\
\hline Moderate-low & $\begin{array}{l}\text { Age } 65-75 \text { years, no history of hypertension, heart } \\
\text { failure or reduced LVEF, or prior systemic emboli }\end{array}$ & 4 & ASA or warfarin \\
\hline Moderate-high & $\begin{array}{l}\text { Age } 65-75 \text { years, no history of hypertension, heart } \\
\text { failure or reduced LVEF, or prior systemic emboli } \\
\text { but have diabetes mellitus or coronary artery disease }\end{array}$ & 6 & Warfarin (target INR 2-3) \\
\hline High & $\begin{array}{l}\text { Age } \leq 75 \text { years with history of hypertension or heart } \\
\text { failure/reduced LVEF OR age }>75 \text { years with no } \\
\text { history of hypertension, heart failure or reduced } \\
\text { LVEF, or prior systemic emboli }\end{array}$ & 12 & Warfarin (target INR 2-3) \\
\hline Very High & $\begin{array}{l}\text { Age }>75 \text { years with history of hypertension or heart } \\
\text { failure/reduced LVEF OR any age with prior emboli }\end{array}$ & 20 & Warfarin (target INR 2-3) \\
\hline
\end{tabular}

$\mathrm{ACCP}=$ American College of Chest Physician LVEF = left ventricular ejection fraction ASA $=$ acetylsalicylic acid

prescribed therapy [18]. It has also been suggested that patient level interventions (such as decision aids) may be a means by which to influence clinical practice - in essence, patients would become the vectors through which evidence could be transmitted to their clinicians [18].

Decision support technology is distinct from general patient education in its focus on the benefits and risks of alternatives (with explicit discussion of the probability and consequences of clinically important outcomes), the tailoring of the information to the particular patient's clinical risk profile, an emphasis on choice, shared decision making, consideration of each patient's values (implicitly or explicitly) during their deliberations, and the expectation that patients will make a choice after completion of the exercise [28]. Decision support technologies vary widely, but audiobooklet decision aids (consisting of an audiotape, a booklet, a personal worksheet, and a physicians' manual summarizing the evidence discussed in the patient booklet) have become a popular mode. Decision aids serve as adjuncts to physician counseling, not a replacement. Despite the growing popularity of decision aids, however, there have been few studies evaluating their impact and most of these had methodologic limitations. Indeed, only 30 of the 221 decision aids identified by the Cochrane Consumers and Communication Group have been tested in randomized studies (only 5 had usual care control arms), all but 2 of these trials had potential unit of analysis errors as they randomized at the level of the patient rather than the health care provider, and all of these studies were of questionable generalizability due to their size (median $n=73$ ) and non-random sampling frames [29]. The impact of decision aids is thus uncertain and is an area clearly in need of more investigation. As pointed out by O'Connor: "optimal study designs should have baseline predispositions, be randomized, have a control group, clearly define the decision, and...determine the impact on long-term decision persistence, health outcomes, health-care utilization, and costs" [29].

\section{Work preceding this trial}

In an earlier paper [28], Man-Son-Hing et al. described the development of an antithrombotic decision aid for patients with NVAF in 1996 (we updated their decision aid to incorporate new studies published from 1996 to 2001 by systematic reviews of the literature). In a randomized trial enrolling 287 participants from the SPAF III Trial, this decision aid was shown to improve patient (1) understanding of the benefits and risks of warfarin and ASA, (2) their estimates of their individual stroke risk, and (3) their comfort with their knowledge levels [30]. However, as the subjects were all being treated within the SPAF III Trial, the investigators were unable to test whether the decision aid could influence physician prescribing. Further, the investigators raised concerns about the generalizability of their results to non-trial participants with NVAF, who tend to be older and have a higher burden of comorbidities, and emphasized the need to evaluate this decision aid in other clinical settings.

\section{Methods}

This study is a prospective, multi-center, two-arm cluster randomized controlled trial being conducted in Edmonton, Ottawa, Toronto, Halifax, and Calgary (all sites in Canada).

\section{Aim of the study}

This study is being done to evaluate whether an evidencebased patient decision aid for patients with NVAF can improve the appropriate use of antithrombotic therapy 
(as defined by the 2001 American College of Chest Physicians (ACCP) Recommendations) by patients and their family physicians [5].

\section{Study design}

Cluster randomization (at the level of the family physician) is being employed in this study such that all eligible patients within any one physician's practice will be allocated either to active intervention (general educational session plus patient decision aid and physicians' manual) or usual care (general educational session). If simple randomization of patients to intervention or usual care were used, the results could be confounded by contamination since physicians receive a physician manual for each patient allocated to the decision aid arm and this may subsequently influence their management of any usual care patients in their practice [31].

Randomization to intervention or usual care is being carried out according to a computer-generated sequence using block randomization (block size of four) with allocation concealment.

\section{Details of the intervention}

The decision aid consists of a 30-page booklet, a personal worksheet, a 50-minute audiotape to guide participants through the booklet and worksheet, and a 7-page physicians' manual summarizing the evidence discussed in the patient booklet with a focus on the 2001 ACCP risk stratification schema and recommendations for antithrombotic therapy [5]. The details of the development and validation of the decision aid employed in the study have already been published [28]. In order to tailor the decision aid to the circumstances of each participant as closely as possible, four versions of the decision aid will be available and patients will receive the version appropriate to their estimated baseline stroke risk (bi-annual risks of 2\%, $4 \%, 12 \%$, or $20 \%$ ). All four versions will present the same background information about AF; the potential consequences of stroke and a major hemorrhage; relative efficacy/bleeding risks with warfarin or aspirin therapy; and importance of INR monitoring for warfarin therapy. The baseline risks of stroke, as outlined above, and the estimates of the potential absolute benefits and risks from warfarin or ASA differ in each version and are presented graphically and numerically (see Canadian Stroke Network website http://www.canadianstrokenetwork.ca for electronic copy of the decision aid). The booklet highlights key points that are further elaborated upon in the audiotape. The 1-page personal worksheet is to be completed by the patient after reviewing the booklet to clarify their personal values regarding desired outcomes, the therapy they are inclined to take, their preferred role in the decision-making process, and to list any questions for their physician. The family physician of each participant in the decision aid arm will be sent a physician manual for insertion into the patient's medical record to assist with future patient discussions. This physician manual distills the information presented in the decision aid into a 7 page document, with an emphasis on the 2001 ACCP risk stratification scheme and recommended antithrombotic therapy (Table 1).

If the decision aid is shown to be beneficial, patients in the control group will be sent a decision aid appropriate to their risk stratum at the close of the study.

\section{Study setting and recruitment of physicians}

A convenience sample of family physicians will be identified in five urban centers across Canada and approached for study participation. Those volunteering to participate will be asked to identify all NVAF patients within their practice using their practice records (most often billing records, but some practices with operational electronic health records will be able to identify eligible patients through this mechanism).

\section{Patient eligibility criteria}

Community-dwelling patients, over the age of 18 , will be included in this study if they have a diagnosis of NVAF (intermittent or chronic) confirmed by electrocardiogram. In those situations where electrocardiograms are not available, a prescription for digoxin will be accepted as confirmation of the clinical diagnosis of $\mathrm{AF}$ as digoxin prescriptions have a specificity of $96 \%$ to $99 \%$ for $\mathrm{AF}$ [32].

Patients will be excluded if they: (1) have valvular AF; (2) are taking warfarin for another condition; (3) are scheduled for cardioversion; (4) have a contraindication to warfarin (pregnancy, women of child-bearing age, history of bleeding diathesis, gastrointestinal or genitourinary bleed in past 6 months, history of intracranial bleed, cirrhosis, esophageal varices, $\mathrm{BP} \geq 180 / 110 \mathrm{~mm} \mathrm{Hg}$ in last month in clinic, excessive alcohol intake, daily use of nonsteroidal anti-inflammatory drug, past intolerance/hypersensitivity to warfarin); (5) have a contraindication to aspirin (peptic ulcer disease in past 6 months, past intolerance/hypersensitivity to aspirin); (6) are cognitively impaired (defined as a score of $\geq 5$ on the Short Portable Mental Status questionnaire) [33]; (7) if their medications are administered by a professional caregiver; (8) if their life expectancy is expected to be less than 12 months; or (9) if they are unable to understand or converse in English.

\section{Study procedures}

Following the identification of potential study patients, each eligible patient will receive a letter signed by their family physician outlining the study and inviting the patient's participation. The study team will subsequently contact any patients who express interest to further 
explain the study, confirm eligibility, invite them to an educational session, and, in consultation with their family physician, ascertain each patient's biannual risk of stroke as per Table 1.

The educational sessions will be conducted by study team members and will involve a standardized lecture about NVAF, the risks and consequences of stroke, an overview of the randomized clinical trial evidence about the average risks and benefits of antithrombotic therapy in NVAF, the importance of compliance with prescribed therapy and, if taking warfarin, the importance of regular monitoring of INR. An open-ended question and answer period will follow each presentation. At the end of the session, the study will be explained again and written consent will be obtained from all patients still willing to participate. Those patients of family physicians allocated to the intervention arm will be given a decision aid with baseline stroke risk appropriate for their risk stratum, and a set of questionnaires assessing their willingness to change, their decisional conflict, and their knowledge about NVAF, stroke, and the risks/benefits of warfarin and ASA. Patients of family physicians allocated to the usual care arm will receive only the questionnaires.

All patients will be contacted by telephone at 3 months, 6 months, and 12 months to determine if they have seen their primary care physician, to document any changes in their therapy, and to explore their satisfaction and compliance with their prescribed antithrombotic therapy. Pharmacy and laboratory/physician records will also be audited at each scheduled follow-up to confirm antithrombotic use and INR data if on warfarin.

Physicians will receive feedback on their participating patients' estimated stroke risk (as per Table 1), current antithrombotic therapy, and, for those patients on warfarin, adequacy of control at 6 months and 12 months. Figure 1 summarizes the study procedures.

\section{Outcome measures}

The primary endpoint will be the use of "appropriate antithrombotic therapy" at 3 months, defined on the basis of the 2001 ACCP recommendations (see Table 1) [5]. Thus, patients in the low risk or moderate-low risk strata who are treated with ASA will be classified as "appropriately treated". Further, patients who are in any category other than low risk (including the moderate-low risk strata) and receive warfarin will be classified as appropriately treated if their INR is within the therapeutic range ( 2 to 3 ) at least $67 \%$ of the time (using interpolation methods similar to those of Rosendaal, incorporating both the frequency of INR measurement and the actual values) [34,35]. Warfarin-treated patients with INRs which are outside the therapeutic range more than $1 / 3$ of the time will not be classified as receiving "appropriate treatment". We chose two thirds as the cutpoint since patients randomized to warfarin in the clinical trials had their INRs within target range on $68 \%$ of days [12].

Since there is no widely accepted criterion for how much time a warfarin-treated patient should be within therapeutic range to be deemed appropriate, we will conduct 2 sensitivity analyses for the primary outcome. First, we will define "appropriate therapy" for warfarin-treated patients as having at least one INR measured per month and an average INR between 2 and 3. Secondly, for warfarintreated patients, we will calculate the proportion of time each patient spends with their INR between 2 and 3 using the Rosendaal method and will compare the means in both arms of the trial [34].

Although patients, their family physicians, and the study investigators will not be blinded to group allocation, outcomes will be ascertained by a study team member who is blinded to group assignment.

Secondary endpoints include the following:

- "Appropriate antithrombotic therapy" at 6 months and 12 months

- Patient's readiness to make a choice at baseline - a previously validated questionnaire [30] will be completed at baseline to determine the patient's willingness to change and to assess their beliefs about who should make treatment decisions [see Additional file 1].

- Patient knowledge after intervention - knowledge about risk of stroke and major bleeding with and without antithrombotic therapy will be tested two weeks after delivery of the intervention using 8 questions with quantitative and multiple choice responses which was used in the earlier randomized trial of the NVAF decision aid [see Additional file 2] [30].

- Decisional conflict - the previously validated O'Connor Decisional Conflict Scale [36] will be utilized two weeks after delivery of the intervention to measure the patient's uncertainty about which therapy to choose, modifiable factors contributing to uncertainty (believing themselves to be uninformed, unclear about values, and unsupported in decision making), and perceived effective decision making [see Additional file 3].

- Acceptability of decision aid - using 9 questions with variable responses (ie. short answer, 5-point Likert scale, yes/no) we will assess patients' views about the acceptability of the decision aid with respect to depth, amount, and 


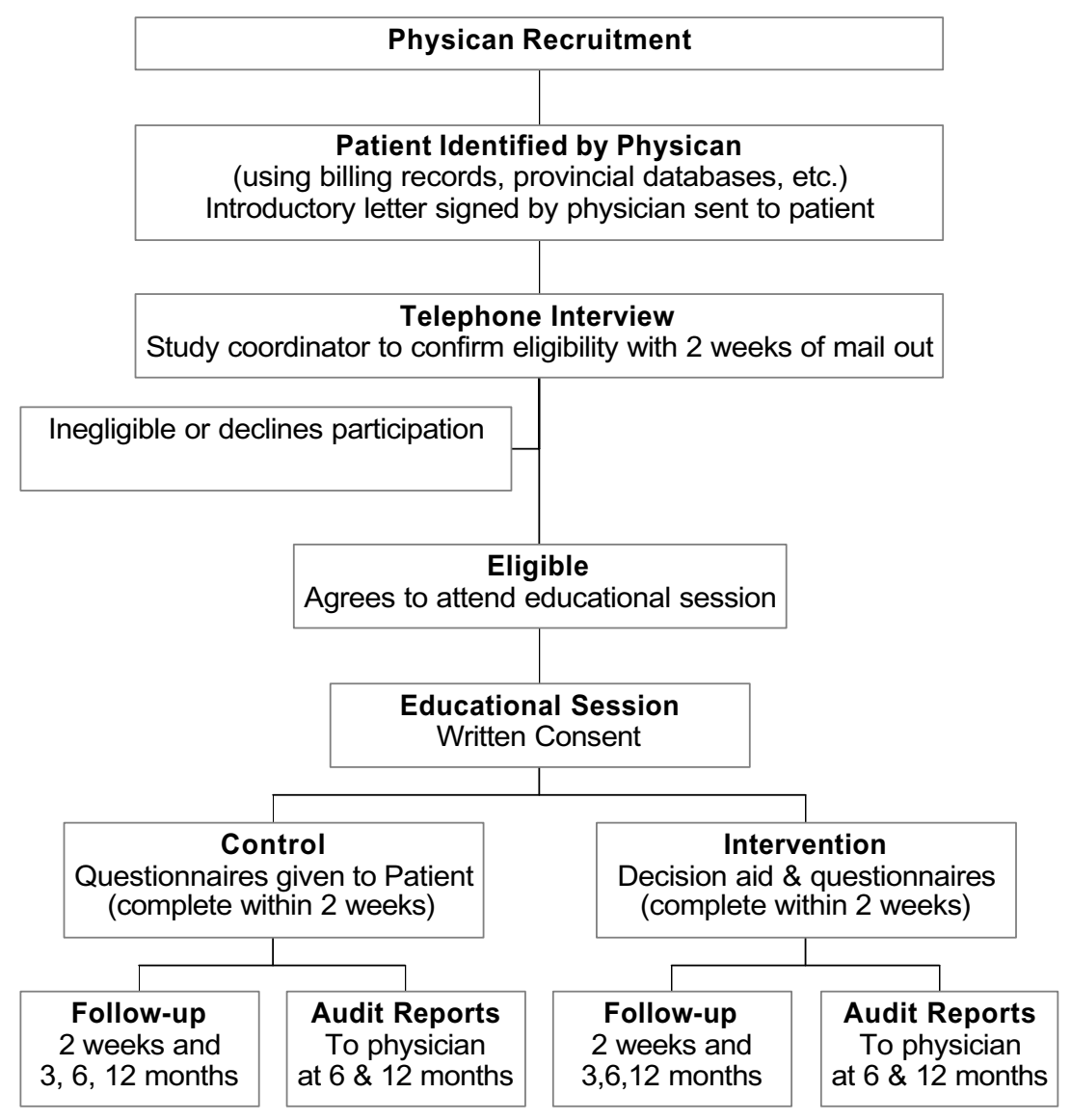

Figure I

Overview of study procedures

format, as well as the usefulness of such a tool in making a decision about therapy [see Additional file 4].

- Satisfaction - patient's satisfaction with current stroke prevention therapy will be assessed at baseline and at 3, 6, and 12-months using a 5-point Likert scale.

- Adherence with therapy - the validated Morisky Scale with a modified 5-point Likert scale response [37] will be utilized to determine patient adherence with prescribed antithrombotic therapy at 3,6, and 12-months.

\section{Sample size}

Previous studies suggest that the rate of antithrombotic use in eligible patients is approximately 60\% [17]. However, the majority of these patients were treated with aspi- rin. Although only one study [38] has looked at the "appropriateness" of antithrombotic use (based on the ACCP risk stratification scheme in use at that time), its findings closely mirror subgroup analysis from our own practice audit [39] in that only 33\% of NVAF patients received "appropriate" antithrombotic therapy (as judged by a panel of clinicians). Thus, it seems reasonable to hypothesize that the rate of "appropriate antithrombotic use" will be in the order of $40 \%$ for unselected patients. Assuming that the rate in the control group remains $40 \%$, and that a $10 \%$ absolute increase in antithrombotic use (to $50 \%$ in the intervention group) is clinically significant, and setting the $\alpha$ error at 0.05 (two-sided) and the $\beta$ error at 0.20 , a sample size of 814 will be required. 
As there will be some loss of power due to between-cluster variability, the sample size has to be adjusted to reflect the cluster randomization [40]. The design effect is the ratio of the number of subjects required using cluster randomization versus the number required with simple randomization and is given by the formula $1+(\mathrm{n}-1) p$, where $\mathrm{n}$ is the average number of subjects per cluster and $p$ is the value of the intra-cluster correlation coefficient. Although the intra-cluster correlation coefficient for the prescription of antithrombotic therapy in these physicians is unknown, we can extrapolate from the North of England Study of Standards and Performance in General Practice which revealed that the $p$ for prescribing by practitioners was often less than 0.01 [31]. As we estimate recruiting 10 subjects from each participating physician, the design effect will be $1+(10-1) 0.01=1.09$. Thus, the required sample size must be increased to 887 .

Allowing for dropouts and losses to follow-up, the sample size has been adjusted to 1100 (550 in each arm). Assuming that an average of 11 patients is recruited from each physician's practice, our target sample size is 50 family physicians in each arm.

\section{Statistical analyses}

Intention-to-treat analysis will be carried out. The primary analysis will be a comparison of the proportion of patients receiving "appropriate antithrombotic therapy" in the intervention and usual care groups at 3 months after intervention. To take into account the cluster randomization, this will be tested using a weighted two sample t-test [41]. Secondary analyses, again using the weighted two sample t-test, will compare long-term compliance in both groups. In order to account for within cluster correlation, a random effects model will be used to assess the difference between groups on the O'Connor Decisional Conflict Scale. Similarly, random effects logistic regression models will be used to investigate what demographic and clinical factors are associated with the use of "appropriate antithrombotic therapy".

An interim analysis will be performed when 3-month follow-up data is available on 400 patients and an independent External Data Committee will review the results and make recommendations about any adjustments to sample size based on the observed cluster size and intra-class correlation coefficient (the study investigators will remain blinded to the results until after the External Data Committee makes recommendations).

\section{Data management}

All data will be collected using standardized data sheets and data collation, entry, and quality assurance will be carried out at the Epidemiology Coordinating and Research (EPICORE) Centre, Division of Cardiology, Uni- versity of Alberta. Data analysis will be done by an independent statistician in EPICORE blinded to group allocation.

\section{Ethical considerations}

Each patient will be given written information about the study and written informed consent will be obtained prior to study inclusion. The study protocol has been approved by the local Research Ethics Boards of the participating centers.

\section{Discussion}

We report the protocol of a cluster randomized trial that aims to determine the effect of an antithrombotic decision aid for patients with NVAF on subsequent use of antithrombotic therapy, patient knowledge, patient decisional conflict and comfort with prescribed treatment, and medication adherence. This will be the largest randomized trial of a patient decision aid for chronic antithrombotic therapy and only the third trial to evaluate decision aids via cluster randomization of health care providers rather than simple randomization of patients. This trial will provide unique information on the effects of patient decision aids on long-term adherence with prescribed therapies (the only other two trials to examine the impact of decision aids on patient adherence with therapy were small (less than 300 patients) and of short duration (6 months) [29].

Although it would be preferable to test the decision aid only in those individuals who are at the point of decision making (and who are not taking aspirin or warfarin at baseline), this population would be logistically difficult to identify and recruitment of sufficient numbers would be unlikely. Information will be collected about whether cases are incident or prevalent, and subgroup analysis to determine whether the decision aid is more effective in recently diagnosed NVAF patients versus prevalent cases will be done.

If this decision aid is found to influence provider or patient behavior, further studies to test the effects of decision aids in other common conditions (for example, inhaled steroids in asthma, ACE inhibitors in heart failure, and statins in hyperlipidemia) will be planned.

\section{The DAAFI investigators are}

Steering Committee: F. McAlister, M. Man-Son-Hing

External Data Committee: D. Sackett, K. Teo, A. Laupacis

Central Coordinating Office: M. Fradette, P. Priest, R. Dupuit, M. Hervas-Malou, S. Blitz, B. Larson 
Participating Sites: M. Man-Son-Hing, A. Jessup-Yabsley, J. Biggs (Ottawa, Canada); F. McAlister, M. Fradette, N. Bell, T. Bungard (Edmonton, Canada); S. Straus, C. Marquez (Toronto, Canada); D. Anderson, J. Cox, S. Quinton, A. McNeil (Halifax, Canada); W. Ghali, P. Gibson, T. Lye (Calgary, Canada).

Participating Physicians: Ottawa, Canada: J Auer, S Bacskai, C Beaulieau, M Berlie, E Biggs, P Boag, D Bowen, E Brown, J Brisebois, M Buczek, R Bushforth, H Charania, T Cregan, C D'Amico, C Dechesne, H Dy, M Edirisinghe, E Elkin, T Faloon, D Finestone, D Guy, D Hans, E Honsl, O Hughes, S Jaffer, R John, K Jones, D Kahlin, C Khazzam, R Lacy, B Lemmex, S Litwin, P Lovett, R Maclean, D McDougall, P McGuire, K McIntosh, B Mehta, B Morris, I Oliver, C O'Neil, I Richardson, A Rosenbloom, M Roy, J Saar, C Sanderson-Guy, J Schatz, G Schneider, T Shapiro, J Shier, R Smolkin, N Spencer, B Syposz, R Tee, S Wager, W Westwick, R Yelle, S Zareef.

Edmonton, Canada: J Bell, N Bell, R Brownoff, G Campbell, A Cave, D Chang, K Chow, T Dusang, F Fairfield, L Fernando, A Fong, N Gray, N Hans, M Hurlburt, P Klemka, E Krikke, D Labuick, T Loewen, K Louie, N McDonald, M Ngan, M Poitras, Q Rizvi, W Read, R Rohloff, S Schipper, E Schuster, S Simon, S Sivalingam, G Spooner, P Twiss, R Wong, J Yu, D Zalasky.

Halifax, Canada: W Acker, M Burnstein, L Clouteri, M Fraser, S Gibbon, S Gowan, E Hanley, J Jim, R Killeen, W Lee, P Leighton, D MacNeil, A MacRae, H Matheson, R Oliver, J Roach, G Roy, R Scovil, O Thompson, J Weider.

Toronto, Canada: E Allen, H Blankenstein, D Collins-Williams, H Erenrich, J Fiala, A Green, B Green, J Kozak, S Shadowitz, W Watson, K Weyman, C Whitmore, E Yeo.

Calgary, Canada: G Black, M Bladek, M Deyholos, P Glimpel, M Goldie, T Jablonski, R Johnson, K Kuzyk, M Libin, M McKague, S Scott, D Topps, A Wooller, C Yam, S Kubik, R Ward, P Aufricht, BC Bell, D Putnam.

\section{Competing interests}

None declared.

\section{Authors' contributions}

FM and MMSH conceived and designed the study; MF is the study coordinator; and FM, MMSH, SES, WAG, PG, $\mathrm{DA}$, and JC are the principal investigators at each participating site. FM and MF drafted this manuscript although all authors provided comments on the drafts and have read and approved the final version.

\section{Additional material}

\author{
Additional File 1 \\ Making Choices about My Medication, questionnaire (secondary \\ endpoint). \\ Click here for file \\ [http://www.biomedcentral.com/content/supplementary/1471- \\ 2261-4-5-S1.pdf]
}

\section{Additional File 2}

My Chances of Stroke or Bleeding in the Next Two Years, questionnaire (secondary endpoint).

Click here for file

[http://www.biomedcentral.com/content/supplementary/1471-

2261-4-5-S2.pdf]

\section{Additional File 3}

My Difficulty in Making This Choice, questionnaire (secondary endpoint).

Click here for file

[http://www.biomedcentral.com/content/supplementary/14712261-4-5-S3.pdf]

\section{Additional File 4}

My Thoughts on the Atrial Fibrillation Decision Aid, questionnaire (secondary endpoint).

Click here for file

[http://www.biomedcentral.com/content/supplementary/1471-

2261-4-5-S4.pdf]

\section{Acknowledgements}

Development and production of the decision aid was funded by the University of Alberta Hospital Foundation, and funding for conducting the trial has been provided by the Alberta Heritage Foundation for Medical Research (AHFMR) and the Canadian Stroke Network. The following investigators hold career salary support: FAM (from the AHFMR and the Canadian Institutes of Health Research), MMSH (from the Ontario Ministry of Health), SES (from the Ontario Ministry of Health), WAG (from the AHFMR and the Canada Research Chairs), and JC (from the Canadian Institutes of Health Research/Regional Partnership Program and the Faculty of Medicine, Dalhousie University). The authors thank Drs. Annette O'Connor and George Wells for their input in early discussions about the design of this trial.

\section{References}

I. Feinberg WM, Blackshear JL, Laupacis A, Kronmal R, Hart RG: Prevalence, age distribution, and gender of patients with atrial fibrillation. Analysis and implications. Arch Intern Med 1995, 155:469-473.

2. Sudlow M, Thomson R, Thwaites B, Rodgers H, Kenny RA: Prevalence of atrial fibrillation and eligibility for anticoagulants in the community. Lancet 1998, 352:1167-II7I.

3. Psaty BM, Manolio TA, Kuller LH, Kronmal RA, Kuller LH, Cushman $M$, Fried LP, White R, Furberg CD, Rautaharju PM: Incidence of and risk factors for atrial fibrillation in older adults. Circulation 1997, 96:2455-2461.

4. Wolf PA, Abbott RD, Kannel WB: Atrial fibrillation: a major contributor to stroke in the elderly. The Framingham Study. Arch Intern Med 1987, 147:1561-1564.

5. Albers GW, Dalen JE, Laupacis A, Manning WJ, Petersen P, Singer DE: Antithrombotic therapy in atrial fibrillation. Chest 200I, I 19:194S-206S. 
6. Hart RG, Benavente O, McBride R, Pearce LA: Antithrombotic therapy to prevent stroke in patients with atrial fibrillation: a meta-analysis. Annals of Internal Medicine 1999, 1 3 I:492-50 I.

7. van Walraven $C$, Hart RG, Singer DE, Laupacis A, Connolly $S$, Petersen P, Koudstaal PR, Chang Y, Hellemons B: Oral anticoagulants vs aspirin in nonvalvular atrial fibrillation: An individual patient meta-analysis. JAMA 2002, 288:244I-2448.

8. Caro JJ, Flegel KM, Orejuela ME, Kelley HE, Speckman JL, MigliaccioWalle $\mathrm{K}$ : Anticoagulant prophylaxis against stroke in atrial fibrillation: effectiveness in actual practice. C M A J 1999, I6I(5):493-497.

9. Frost L, Johnsen SP, Pedersen L, Toft E, Husted S, Sorensen HT: Atrial fibrillation or flutter and stroke: a Danish populationbased study of the effectiveness of oral anticoagulation in clinical practice. J Intern Med 2002, 252(I):64-69.

10. Gottlieb LK, Salem-Schatz S: Anticoagulation in atrial fibrillation. Does efficacy in clinical trials translate into effectiveness in practice? Arch Intern Med 1994, I 54(I 7): 1945-1953.

II. Kalra L, Yu G, Perez I, Lakhani A, Donaldson N: Prospective cohort study to determine if trial efficacy of anticoagulation for stroke prevention in atrial fibrillation translates into clinical effectiveness. BMJ 2000, 320:1236-1239.

12. Evans A, Kalra L: Are the results of randomized controlled trials on anticoagulation in patients with atrial fibrillation generalizable to clinical practice? Arch Intern Med 2001, |6 I: |443-1447.

13. Baggio D, Madore F, Lalonde G: Oral anticoagulant therapy for heart disease: results in actual cardiology practice. Can J Cardiol 2000, 16(2):|53-16|.

14. Gage BF, Cardinalli AB, Albers GW, Owens DK: Cost-effectiveness of warfarin and aspirin for prophylaxis of stroke in patients with nonvalvular atrial fibrillation. JAMA 1995, 274: $1839-1845$.

15. Atrial Fibrillation Investigators: Risk factors for stroke and efficacy of antithrombotic therapy in atrial fibrillation: analysis of pooled data from five randomized controlled trials. Arch Intern Med 1994, I54:| 449-| 457.

16. Stroke Prevention in Atrial Fibrillation Investigators: Risk factors for thromboembolism during aspirin therapy in patients with atrial fibrillation: the stroke prevention in atrial fibrillation study. J Stroke Cerebrovasc Dis 1995, 5: 147-I57.

17. Bungard TJ, Ghali WA, Teo KK, McAlister FA, Tsuyuki RT: Why do patients with atrial fibrillation not receive warfarin? Arch Intern Med 2000, 160:41-46.

18. McAlister FA: Atrial fibrillation, shared decision making, and the prevention of stroke. Stroke 2002, 33:243-244.

19. Protheroe J, Fahey T, Montgomery AA, Peters TJ: The impact of patients' preferences on the treatment of atrial fibrillation: observational study of patient based decision analysis. $B M$ J 2000, 320:1380-1384.

20. Thomson R, Parkin D, Eccles M, Sudlow M, Robinson A: Decision analysis and guidelines for anticoagulant therapy to prevent strokes in patients with atrial fibrillation. Lancet 2000 355:956-962.

21. Man-Son-Hing M, Laupacis A, O'Connor A, Wells G, Lemelin J, Wood W, Dermer M: Warfarin for atrial fibrillation. Arch Intern Med 1996, 156: |84|-1848.

22. Devereaux PJ, Anderson DR, Gardner MJ, Putman W, Flowerdew GJ, Brownell BF, Nagpal S, Cox JL, Fahey T: Differences between perspectives of physicians and patients on anticoagulation in patients with atrial fibrillation: observational study. BMJ 200I, 323:1-7.

23. Sudlow $M$, Thomson $R$, Kenny RA, Rodgers $H$ : A community survey of patients with atrial fibrillation: associated disabilities and treatment preferences. Br J Gen Pract 1998, 48: 1775- 1778

24. Bungard TJ, Ghali WA, McAlister FA, Buchan AM, Cave AJ, Hamilton PG, Mitchell LB, Shuaib A, Teo KK, Tsuyuki RT: The relative importance of barriers to the prescription of warfarin for nonvalvular atrial fibrillation. Can J Cardiol 2003, 19:280-284

25. Bungard T, Ghali WA, McAlister FA, Buchan AM, Cave AJ, Hamilton PG, Mitchell B, Shuaib A, Teo KK, Tsuyuki R: Physicians, perceptions of the benefits and risks of warfarin for patients with nonvalvular atrial fibrillation. C M A J 200I, 165:30I-302.

26. Monette J, Gurwitz JH, Rochon PA, Avorn J: Physician attitudes concerning warfarin for stroke prevention in atrial fibrilla- tion: results of a survey of long-term care practitioners. J Am Geriatr Soc 1997, 45: 1060-1066.

27. Kutner M, Nixon G, Silverstone F: Physicians' attitudes toward oral anticoagulants and antiplatelet agents for stroke prevention in elderly patients with atrial fibrillation. Arch Intern Med 199I, I5I:1950-1953.

28. Man-Son-Hing M, Laupacis A, O'Connor AM, Hart RG, Feldman G Blackshear JL, Anderson DC: Development of a decision aid for patients with atrial fibrillation who are considering antithrombotic therapy. J Gen Intern Med 2000, 15:723-730.

29. O'Connor AM, Stacey D, Entwistle V, Llewellyn-Thomas H, Rovner $D$, Holmes-Rovner M, Tait V, Tetroe J, Fiset V, Barry M, Jones J: Decision aids for people facing health treatment or screening decisions (Cochrane Review). In: The Cochrane Library Issue I Chichester, UK: John Wiley \& Sons, Ltd; 2004.

30. Man-Son-Hing M, Laupacais A, O'Connor AM, Biggs J, Drake E, Yetisir E, Hart RG, for the Stroke Prevention in Atrial Fibrillation Investigators: A patient decision aid regarding antithrombotic therapy for stroke prevention in atrial fibrillation. A randomized controlled trial. JAMA 1999, 282:737-743.

31. Underwood M, Barnett A, Hajioff S: Cluster randomization: a trap for the unwary. Br J Gen Pract 1998, 48: $1089-1090$

32. Sudlow M, Rodgers $H$, Kenny RA, Thomson R. Identification of patients with atrial fibrillation in general practice: a study of screening methods. BMJ 1998, 317:327-328.

33. Pfeiffer $E$ : $A$ short portable mental status questionnaire for the assessmentof organic brain deficit in elderly patients. $J$ Am Geriatr Soc 1975, 23:433-44I.

34. Rosendaal FR, Cannegieter SC, van der Meer FJ, Briet E: A method to determine the optimal intensity of oral anticoagulant therapy. Thromb Haemost 1993, 69:236-239.

35. Wilson SJA, Wells PS, Kovacs MJ, Lewis GM, Martin J, Burton E, Anderson DR: Comparing the quality of oral anticoagulant management by anticoagulation clinics and by family physicians : a randomized controlled trial. CMAJ 2003, 169:293-298.

36. O'Connor A: Validation of a decisional conflict scale. Medical Decision Making 1995, 15:25-30.

37. Mitchell C, Johnson JA, Maxwell CJ, Vik SA, Hogan DB, RomonkoSlack L, Patten SB, Copeland M, Couchman S, Matson B, Harbridge T: Reliability of likert-type versus dichotomous response options for a standardized self-report measure of medication compliance behaviour [abstract]. Can J Clin Pharmacol 200I, 8:36.

38. Antani MR, Beyth RJ, Covinsky KE, Anderson PA, Miller DG, Cebul RD, Quinn LM, Landefeld CS: Failure to prescribe warfarin to patients with nonrheumatic atrial fibrillation. J Gen Intern Med 1996, II:713-720.

39. The Clinical Quality Improvement Network Investigators: Thromboembolic prophylaxis in 3575 hospitalized patients with atrial fibrillation. Can J Cardiol 1998, 14:695-702.

40. Donner A, Birkett N, Buck C: Randomization by cluster: sample size requirements and analysis. Am J Epidemiol I98I, I | 4:906-9|4.

4I. Donner A, Klar N: Confidence interval construction for effect measures arising from cluster randomization trials. Journal of Clinical Epidemiology 1993, 46:123-131.

\section{Pre-publication history}

The pre-publication history for this paper can be accessed here:

http://www.biomedcentral.com/1471-2261/4/5/prepub 